\title{
Small and Medium-sized Enterprise Office LAN Construction Scheme
}

\author{
Zhuoyu Mo \\ Chongqing business vocational college
}

\begin{abstract}
-through the development of small and medium-sized enterprise network system of data statistics, increasingly strong demand for network out of the small and medium-sized enterprises is discussed in this paper, after analyzing the current situation of small and medium-sized enterprise network at the same time, build a set of suitable for the development of the enterprise itself the decision of the network environment is necessary; Formed through the network design, network management scheme, network basic configuration scheme based on safety, these three aspects of small and medium-sized enterprise network are discussed, using the experience and cases to elaborate explanation of various key issues encountered by building LAN; Finally conclude that a majority of small and medium-sized enterprises from the network, management, the implementation of the design phase should follow the general principles. This article mainly research in wireless local area network (LAN) in which an analysis of the small business needs, and how to form a economic, security, application of wireless local area network (LAN) system, combined with the actual simulation framework to build a safe construction scheme of the wireless local area network (wlan).
\end{abstract}

Keywords-small and medium-sized enterprises; Local area network (LAN); Construction scheme

\section{INTRODUCTION}

With the progress of society continuously, also in the rapid development of science and technology, the Internet has become a anyone would not be unfamiliar words, each person may come into contact with the Internet every day. For an enterprise, the network build or not has begun to gradually influence the acquisition of enterprises the pace of information technology in the future. Even for some enterprise information network has become the indispensable means a work, they education departments, large enterprises, to form a network in areas such as the enterprise authority has been increasingly mature, and this paper is aimed at another group that nots allow to ignore, small and medium-sized enterprises to form a LAN network. Society in progress, the wireless network is becoming more and more by the masses, small and medium-sized enterprises (smes) to the network demand is also increasing, but the resulting is facing some problems, the selection of design scheme, the money, the daily maintenance of network security, network management personnel, etc. How can meet the needs of growing small and medium-sized enterprises to network, at the same time to try to ease the burden and as a result, is a problem worthy to be discussed.

\section{THE CURRENT SITUATION OF THE DEVELOPMENT OF \\ SMALL AND MEDIUM-SIZED ENTERPRISE NETWORK ANALYSIS}

Construction of four modernizations synchronization in the country today, informationization level has already reached a high position. Now as for domestic, small and medium enterprises generally realized LAN cable network coverage. But as the office in the form of informatization and networking, socialization, office anytime and anywhere even more important, more and more people began to have a computer with a wireless network card terminals, such as: mobile phone, tablet, etc., employees need more use of spare time to do what is good for your work, so more and more portable computer terminal into the enterprise. So, today, whether business or personal, for the dependence of the wireless network has become very high, "to be able to get information anytime and anywhere" has become the general food in the spirit of enterprise employees. Traditional small and medium-sized enterprise network cable, however, there is a lot of "blind spots" network, such as: restaurant, large conference room,gymnasium, exhibition hall and so on how many unfavorable network wiring facilities connected to the Internet? In office buildings and other occasions how to realize the people at the same time on the Internet, breakthrough the limit of network node problem? Wireless local area network (LAN) can solve this problem. At present, to the requirement of small and medium-sized enterprise wireless local area network construction and main functions are: high bandwidth, radio management secret,reliable performance, high safety, low cost, etc. Using wireless network technology to further extend the enterprise wireless network coverage can further improve enterprise network environment, and improve management efficiency and level,to promote enterprise information construction and the development of the enterprise[1].

As basic components in the national economy, the degree of enterprise informatization, network is the key of national information construction and the foundation, our country small and medium-sized enterprises more than $99 \%$ of the total, the sales revenue accounted for $57 \%$ of the total, small and medium-sized industrial enterprises has accounted for $60 \%$ of total industrial GDP, therefore, for small and medium-sized enterprise informatization level, to some extent, more able to reflect the current situation of Chinese enterprise informatization. Small and medium-sized enterprise information demand also represents the Chinese enterprise comprehensive upgrade 
and reform, an important aspect of information market demand.

\section{THE SMALL AND MEDIUM-SIZED ENTERPRISES}

DEMAND ANALYSIS OF THE WIRELESS LOCAL AREA

\section{NETWORK (WLAN)}

Through the analysis of the statistical data is not hard to see, in addition to the information industry, most of the enterprises, especially a service-oriented enterprises, foreign trade business process gradually shifting from the reality to the network. Because of big business lead, lead to other small and medium enterprises to update the network demand is also becoming more and more urgent. Combining with the statistics of network status quo, to analysis the network status of many enterprises cannot satisfy completely the requirements of the development of the enterprise itself. ${ }^{[2]}$ The reformation, it is imperative to upgrade. After a period of investigation and visit, in this paper, the following conclusions: 1 . Most of the small and medium-sized enterprises possess the basic condition to extend the network need 2. Network managers have certain basic specialized knowledge, after a certain amount of training can deal with after transforming network conditions. 3 . The cost will not very high, the money is in the scope of most enterprises are able to accept, but to form a network solution cannot too complex the difficulty of the maintenance and upgrade lies in network security, can make the actual enterprise itself according to the need of different solutions.

With the rapid development of network applications, the expansion of intelligent mobile terminal wireless networks provide users with a lot of convenience, can anytime anywhere can enjoy more business, free access to the network, safety and security of the network, it is also the inevitable trend of social development experience. It also encouraged in adapt to the environment and access rate and $3 \mathrm{G}$ technology complement each other of the rapid development of WLAN wireless local area network (LAN), have become an indispensable a development needs of small and medium-sized enterprises. [4]Wireless LAN WALN as an extension of the Ethernet cable, using radio frequency technology constitute local area network, is a kind of dinner-table data transmission system. Generally work in unlicensed spectrum due to the wireless local area network (LAN) equipment, maintenance, and often in the mobile terminal on the use of frequencies do not need high license fees, and WLAN technology becoming mature, makes the application of WLAN has gone from a simple extension of cable network expands, become indispensable to small and medium-sized enterprise especially hotspots in high speed wireless data is one of the means by which people, have great potential for application.

\section{SMALl AND MEDIUM-SIZED ENTERPRISE OFFICE}

\section{NETWORK TO FORM A DESIGN}

Through the small and medium-sized enterprises of the most commonly used two kinds of access network technology were analyzed, and the comparison and analysis of the properties of the two, can make the enterprise have choose the way to determine the access.
To network construction cost, at the same time to make the enterprise into a roughly estimate the investment budget. In order to determine whether or not suitable for a network to form a design scheme of enterprise itself. ${ }^{[5]}$

\section{A. The traditional local area network (LAN)}

Traditional LAN first need to connect computer nodes are generally in more than 60 sets, and the distance between each node is relatively far, generally more than $150 \mathrm{~m}$ even further, if the enterprise office environment demand is higher, on the performance of the network to network download conveying speed also to have certain requirements, you can use the fiber optic medium to connect to the entire enterprise campus backbone network, improve the quality of the network. LAN can be used in a two layer structure, namely for the various nodes connected to switch desktop switches layer and center. Each node of the desktop switches connected to a central switch. Central switch can use a slightly high-end enterprise switches, can provide multiple gigabit network port.

\section{B. Of the wireless local area network (LAN)}

Wireless LAN is now of choice for small and medium-sized enterprise office LAN construction, set up enterprise wireless network must pay attention to the following aspects: one is security, may at any time transmission in the wireless local area network (LAN) the core of company confidential information, if the company's confidential documents for misrepresentation may be related to the lifeblood of the company, ensure the safety is the first principle of a network. Stability, belong to the network channel is also part of the enterprise must real-time interactive channel, if paralysis or congestion, at any time may cause a great loss to the enterprise, the wireless local area network (LAN) to form must ensure that his smooth general characteristic, stability.[6] Three is controllable, the wireless local area network (LAN) must be humanized design, convenient for enterprise employees in control and self management, also need supervision of shielding function if necessary. Four is economy, small and medium enterprises generally for the purpose of profit, profit is in order to survive, the economy is an issue they have to think about, and the small and medium-sized enterprise capital turnover mostly nervous, and not a lot of money to form a wireless local area network (LAN), economical become an important indicator of their consideration. Fifth, extensibility, the network update too fast, that must be considered when designing its continuity and extensibility, convenient enterprises improve the upgrade in the future.

\section{The regional network to form details}

\section{1) The choose and buy of products}

Wireless local area network (LAN) to form the main need two hardware: wireless repeater and wireless receiver. According to computer configuration model to determine the small and medium-sized enterprises to buy different wireless receiver, if the desktop computer, can choose two kinds of wireless network card USB and PCI interface. If for laptops, first to see if their own wireless networks connect employees device, if any can be used directly, without optional USB and CMCIA two wireless network 
card interface. Here mainly refers to the wireless repeater which has the function of wireless transmitting switches and wireless router, etc. ${ }^{[7]}$ With the continuous development of science and technology of modern society, the router is also before a single routing functions to the routing, modems, switches, wireless transmitting, such as multi-functional shift, due to the complexity of the performance of diversification, so the price will be relatively high. When these products of choose and buy should pay attention to several major indicators: 1 . The interface type, according to their own small and medium-sized enterprises can adapt itself to the computer type to choose and buy is corresponding the wireless receiver of interface. 2. The compatibility, wireless devices must have compatibility of choose and buy, between various hardware devices to be able to normal hardware access, information exchange, so when choosing multiple wireless devices, must choose compatible with each other or support the same standard product. 3. The transmission efficiency and transmission efficiency basically see the distance of transmission, transmission rate and penetrating power, the faster the rate of network transmission distance is far, the more the better, the penetrating power. Mainly these three aspects, and other security, such as transmission distance may be bought as a standard.

\section{2) Wireless network hardware installation}

Hardware mainly wireless router installation, the installation of the installation of the wireless network card and wireless switches, according to the choose and buy of enterprise computer and type of wireless network card one-to-one matching USB wireless network card is relatively simple, is directly connected, PCLS interface power to open the case, put the photo on the interface, and then open the computer, let people drive disc, step by step according to the computer prompts to install the network card drive, install the desktop will appear after the completion of a wireless network connection icon, the computer will display the wireless icon and the bottom right hand corner. The laptop installation Settings, too. ${ }^{[8]}$ Wireless router installation should take into account the wireless launch will have to take care of all the office area, also want to consider the location of the total network wiring, and pay attention to play a good role at the same time can not affect beautiful, must also have a computer cable, ensure that after the network configuration Settings. If the router wireless could not cover all the office area, you will need to pick up one or more wireless switches, to cover all the office area, but also to design network cable to connect switches and routers.

\section{3) LAN port}

LAN port is internal line from enterprise users, itself exists some router LAN port, can be directly under the switch. Some network administrator will router first received a backbone switch, received the general switch down again. These two kinds of practice, which is suitable for large network traffic, the application of the general small and medium-sized enterprise applications, the router's LAN port is can be forwarded as broadband. So it is relatively simple in hardware configuration of a kind of way. Experience, points out that to be a reliable good security network configuration has the efficiency of IP management is very important. IP is the computer where the Internet address, manage IP address to be effective management, ability to have a problem of computer or prevent attacks to control them. For network management, in IP management is the need to focus on matters, mainly for computer use DHCP server to issue fixed IP, fixed IP address, prevent not by allowing the computer to surf the Internet and group management and so on four important projects.

\section{V.THE NETWORK MANAGEMENT SCHEME}

Due to the high degree of standardization of Ethernet technology, mature technology, wide application, high cost performance, good support for IP address, become the development trend of access network and local area network (LAN). However, due to the application of Ethernet technology widely and its openness, also brought some security issues. Especially when the network by the original single business carrying into more business carrying, the security problem of the impact of increasing cognition for the majority of small and medium-sized enterprises, has gradually affected the deployment and development of the business. At present the common attacks including ARP packet access network flooding attack, ARP "middlemen" attack, DHCP/ARP packet flood attack, IP/MAC spoofing attacks, etc.

\section{THE CONCLUSIONS}

To sum up, due to the wireless local area network (LAN) due to its advantages of high efficiency, low cost, flexible and fast, has become the small and medium-sized enterprises (smes) familiar with the product. But the network security problem is a problem to be solved, so the suggestion for some core of confidential information, do not communicate through the network, so as not to be used or stolen.

\section{REFERENCES}

[1] Miss Ann [1]. Small and medium-sized enterprise network construction scheme discussion [J]. Journal of jiangsu science and technology information, 2013, 11:42-43.

[2] Cheng wei. [2] medium enterprise LAN construction scheme based on enterprise information application $[\mathrm{J}]$. Journal of digital users, 2013, 11:7.

[3] Wu Qin. Analyses the safety management of small and medium-sized enterprise office LAN [J]. Computer CD software and applications, 2012, 22:159 + 161

[4] YanYanHua. Office LAN construction, maintenance and safety analysis [J]. China's new communications, 2011, 12:84-91.

[5] Janet wang LAN form analysis [J]. Journal of information and computer (theory), 2011, 10, $114+116$.

[6] Tian Fu. Discuss wireless local area network (LAN) in small and medium-sized enterprises demand analysis and form a $[\mathrm{J}]$. Journal of electronics, 2013, 12:129.

[7] Liao Jiyao. Enterprise office LAN construction analysis [J]. Journal of wit, 2010, 27:53.

[8] kindle. Small and medium-sized enterprise network office automation system development [D]. University of electronic science and technology, 2011.

[9] MoZhuoYu, chongqing pearls, 1981.3, associate professor, chongqing business vocational college, computer application technology, computer mathematical statistics, 